\title{
Research Article \\ The Impact of Different Carbon Emission Policies on Liner Shipping
}

\author{
Xiangang Lan $\mathbb{D}^{1}{ }^{1}$ Xiaode Zuo, ${ }^{1}$ and Xia Tang ${ }^{2}$ \\ ${ }^{1}$ School of Management, Jinan University, Guangzhou 510632, China \\ ${ }^{2}$ Collaborative Innovation Center for Transport Studies, Dalian Maritime University, Dalian 116026, China \\ Correspondence should be addressed to Xiangang Lan; lanxiangang19@163.com
}

Received 29 January 2020; Revised 18 June 2020; Accepted 30 June 2020; Published 31 July 2020

Academic Editor: Garth L. Fletcher

Copyright (C) 2020 Xiangang Lan et al. This is an open access article distributed under the Creative Commons Attribution License, which permits unrestricted use, distribution, and reproduction in any medium, provided the original work is properly cited.

\begin{abstract}
This paper considers the influence of different carbon emission policies for liner shipping. The transportation optimization models under four different forms of carbon emission policies (no carbon emissions constraints, carbon emissions tax, carbon caps, and carbon cap-and-trade) are developed. A real case is given to demonstrate the effectiveness of the proposed models and comparative analysis of the impact of different carbon emission policies on shipowner's profit and ship carbon emission. It is shown that the carbon caps form is the most direct method for reducing emission; the form of carbon emissions tax is a mandatory measure, which has the greatest impact on the profit of shipping companies; carbon cap-and-trade forms have weaker emission reduction effects, it is easier for enterprises to actively implement emission reductions and be highly motivated in the long run.
\end{abstract}

\section{Introduction}

Carbon emission control policies will affect the speed decision, which is closely related to the optimization of liner transportation [1]. Increased awareness of environmental protection, the shipping emissions cause the attention of people. In July 2011, at the 62nd meeting of the Marine environmental protection committee, International Maritime Organization (IMO) adopted the VI amendment to the annex to the international convention for the prevention of pollution from ships, the first mandatory law and regulation related to carbon emission reduction applicable to ships of all countries. In June 2013, the European Union (EU) formulated policies to reduce emissions in the shipping industry. As an important means to effectively reduce carbon emissions and promote the sustainable development of the shipping industry, common carbon emission policies at present mainly include carbon emissions tax, carbon caps, and carbon cap-and-trade [2]. The European emissions trading system (EU ETS), which was the first to implement carbon caps and caps-and-trade, has become the world's largest market for carbon emissions trading [3]. Different carbon emission policies have different impacts on shipping, and which policies are more suitable for the shipping industry to be further studied. For enterprises, the implementation of different carbon emission policies has brought new challenges to the operation and management of enterprises, making the management decisions of enterprises more complicated. It is necessary to conduct in-depth discussions on their emission reduction effects and their impact on enterprises. Therefore, the study on the impact of different carbon emission policies on liner shipping has the significance of theory and practicability.

Shipping is the most energy-efficient way of transporting long-distance cargo, much less carbon emissions than air, rail, and road transport [4]. However, the European Environmental Protection Agency's "Impact of International Shipping on Air Quality and Climate Change in Europe" issued in 2013 pointed out that shipping is "one of the most unregulated sources of atmospheric pollutants". Carbon emissions do not equal pollutants and mostly considered as greenhouse gases (GHG). IMO estimated the level of GHG emitted by ships in 2007 at 1046 million tons of CO2, about 3.3\% of the global emissions, and if no action is taken, these 
emissions are expected to increase by 150-250 percent by 2050 [5]. Therefore, shipping is considered to be an important source of global greenhouse gas emissions [6]. The emission of GHG from shipping has attracted increasing attention as a global issue over the past decade [7]. IMO has set a goal of reducing GHG emissions from existing ships by $20-50 \%$ by 2050 [8]. IMO has developed the concept of a Sustainable Maritime Transportation System for the "safe, secure, efficient and reliable transport of goods across the world, while minimizing pollution, maximizing energy efficiency and ensuring resource conservation" [9]. In this context, it is more practical to study the issue of shipping carbon emissions.

To tackle the above, we adopt the following methodological steps as summarized below:

(i) Constructing the optimal decision model of liner transportation based on the profit of the shipping company by using the fuel consumption law of the host, regardless of the carbon emission policy

(ii) Using the relationship between fuel consumption and carbon emissions, construct a liner transportation optimization decision model that considers carbon emissions tax, carbon caps, and carbon cap-and-trade

(iii) The model was verified by the real case of COSCO (China Ocean Shipping (Group) Company) SHIPPING Lines Co., Ltd. and the results were discussed and analyzed

Under this context, the purpose of this paper:

(1) Analysis of the impact of different carbon emission policies on shipping company's transportation optimization decisions and profits, exploring the role of different carbon emission policies in reducing emissions. On the one hand, it can better guide enterprise practice, on the other hand, it provides a basis for policy makers to correctly select applicable carbon emission policies

(2) Study the differences between carbon emissions tax and carbon cap-and-trade in terms of effect cost, emission reduction effect, and future adaptation to sustainable development. Provide an important reference for the formulation and implementation of carbon emission policies

(3) Exploring the impact of market emission reduction policies on corporate costs through marginal abatement costs. It reveals the internal causes of corporate emission reduction decisions and provides a strong basis for formulating policies

(4) Multiangle analysis of shipping emission reduction issues, providing reference for the sustainable discovery of the shipping market and the formulation of long-term emission reduction policies

Most of studies consider a single carbon emission policy, such as carbon emissions tax or carbon cap-and-trade, this paper studies the impact of four different carbon emission policies on liner shipping. The rest of the manuscript is organized as follows: Section 2 reviews the relevant literature. Section 3 describes the problem under study, while Section 4 presents the mathematical models for the problem with four different cases: model without carbon emission tax, model considering carbon caps, model considering taxing emissions, and model considering carbon cap-and-trade. Section 5 describes the numerical example and performs computation results analysis. Finally, in Section 6, we sum up the findings of this research.

\section{Literature Review}

This paper is related to two streams of research in literature, carbon emission for shipping, and carbon emission policies for shipping. With the increasing importance of environmentally sustainable development in the world, more and more scholars have studied ship carbon emission and ship transport optimization. The carbon emission of the shipping industry is closely related to the fuel consumption of ships $[10,11]$. Armstrong [12] discussed vessel optimization initiatives that made a difference in minimizing fuel consumption and contributed to low carbon shipping. Cariou [13] used second-hand data, an accurate analysis of the impact of slow sailing on $\mathrm{CO}_{2}$ emissions from liner shipping since 2008. Lindstad et al. [14] investigated the effects of speed reductions on the direct emissions and costs of maritime transport. Woo and Moon [8] has studied three aspects: (1) to analyze the relationship between voyage speed and the amount of $\mathrm{CO} 2$ emissions and estimate the changes of slow steaming in liner shipping; (2) to analyze the relationship between voyage speed and the operating costs on a loop; and (3) to find the optimal voyage speed as a solution to maximize the reduction of $\mathrm{CO}_{2}$ emissions at the lowest operating cost, thus satisfying the reduction target of IMO. Yin et al. [15] looked into the questions of how slow steaming could save bunker consumption and bring benefits to the environment. Haakon and Eskeland [16] proposed three measures to reduce energy consumption, and carbon dioxide emissions from maritime transport were slow-down navigation, larger vessels, and a slenderer hull design. Wong et al. [17] proposed a sustainability model based on deceleration navigation decision to balance the relationship between deceleration navigation decisions and fuel costs, schedule delays, and carbon emissions. Psaraftis [18] explored the "speed optimization and deceleration navigation" to reduce the effects and defects of ship emissions.

Kim et al. [19] studied the ship speed optimization problem with the objective of minimizing the total fuel consumption. Kim et al. [20] addressed the problem of determining the ship speed, fleet size, and chartered ship number subject to environmental regulations consisting of a carbon tax and an emission trading scheme. Corbett et al. [21] discussed the policy impact of fuel tax and speed limit on carbon dioxide emissions. Psaraftis and Kontovas [22] explored the impact of various offshore emission reduction policies on maritime logistics. Windeck and Stadtler [23] explored the potential impact of cap and trade regimes on container 
shipping companies and European port organizations. Kim et al. [20] studied the ship speed, fleet size, and ship number decision problem under the constraints of carbon tax and carbon emissions trading. Franc and Sutto [24] focused on the principle of a cap-and-trade system and explored the potential impacts of the implementation of such a measure on the organization of containerized shipping lines and European ports. Wang and $\mathrm{Xu}[1]$ considered three different forms of carbon emission models without carbon emission tax, emission taxation exceeding a certain threshold, and carbon emission taxation to construct a speed decision model. Chang and Danao [25] provided an empirical research using structural equation modeling to identify the factors that motivate shipping firms to adopt green shipping practices; the findings show that shipping firms are motivated to adopt GSP mostly by industrial norms set by institutionalized associations. Michaelowa and Krause [26] discussed the possible impact of ship greenhouse gas emissions and climate change on ships. It outlines the policies and measures that should be taken to reduce greenhouse gas emissions from shipping in a cost-effective manner. Chen and Wang [27] studied the optimal ordering and transportation options under different carbon emission reduction policies. Mæstad et al. [28] summarized the main results from the project Norwegian and international climate policy consequences for shipping. Lirn et al. [29] indicated that a greener policy had a direct and positive influence on both the greener ships and the greener suppliers' factors. Xing et al. [30] considered two carbon emission policies to explore the problem of container ship speed optimization and fleet scheduling. Zhu et al. [31] investigated the potential impact of an open maritime emissions trading system (METS) on individual containership operators' fleet composition strategies and $\mathrm{CO} 2$ emissions levels.

Most of the liner shipping studied under the carbon emission policy only considers a single carbon emission policy, such as carbon emissions tax or carbon cap-and-trade. A few studies on policy comparisons are also based on the macro level. Therefore, the existing literature lacks a comparative study on the impact of different carbon emission control policies on liner transportation. In order to better analyze the impact of different carbon emission policies on transportation enterprise optimization decision-making and profit, and to explore the role of different carbon emission policies in promoting the sustainable development of the shipping industry, it is necessary to simultaneously study the decisions under various carbon emission policies. The model, on the one hand, can better guide business practices, and on the other hand, provide a basis for policy makers to correctly select applicable carbon emission policies.

\section{Problem Description and Notations}

In this section, we describe the problem under study, while we further provide all relevant assumptions. On an intercontinental container liner route consisting of multiple ports, according to the preestablished schedule, the shipping company berth at a fixed port on the fixed route, and carry out repeated container cargo transportation services for the cargo owner according to the prescribed operating rules, and collect the freight according to the fixed freight rate. When grasping the container freight demand and freight rate between any ports on the route during the study period, the transportation revenue can be considered to be basically the same, and the profit is equal to the income minus the cost. The cost includes host fuel costs, auxiliary fuel costs, fixed operating expenses, handling costs, port charges, and carbon emissions costs. Based on the speed of the ship, the number of ships, and the choice of ship type as the decision variables, constructs the nonlinear optimization model of the shipping company's profit.

Take the fixed route of container liner shipping fleet as the research object, and assumes that (1) the service level and charging standard of each port of the research route are the same, and the various expenses and average loading and unloading efficiency are known; (2) the freight demand between ports. It is known and basically does not change; (3) the condition of the route and the order of calling the port have been determined, and the ship is sailing under normal navigation conditions, no accidents occur during the voyage, and each segment sails at the same speed; (4) the same ship type is used on the same route, and the operating ship is weekly service; (5) the pilot time of the ship entering and leaving each port is the same; (6) the carrying capacity of the ship and the demand between the ports are measured by the number of containers, and the goods are FCL transportation.

The symbols used in this paper have the following meanings. $M$ represents all types of ships; $n_{m}$ denotes the number of $m$ type of ships allocated for liner route (ships); $x_{m}$ is a 0,1 variable; and $x_{m}$ equals 1 to indicate the selected $m$ types of ships, otherwise, it is not selected; $v_{m}$ represents the sailing speed of the $m$ type of vessel in nautical miles per hour, which takes a value between the minimum speed $v_{m}^{\min }$ and $v_{m}^{\max }$ the vessel design speed $v_{m}^{0}$; $t^{s}$ represents the total time (in hours) that a ship spends at sea on a roundtrip; $q_{i j}$ represents weekly demands in TEUs from port call $i$ to port call $j ; D$ represents the distance of whole voyage on the route; $N$ represents the number of port calls on the route and the port calls are indexed from 1; and the $N$ th port call refers to the vessel sailing back to the first port; $r_{i j}$ represents the revenue from satisfying the demand (USD/TEU) from port call $i$ to port call $j$; $T$ represents the total time (in hours) that a ship spends on a round-trip; $t_{\text {pil }}$ represents the time (in hours) of approach pilotage of vessel; $l$ denotes port efficiency (TEU/hour); $c_{m}$ represents fixed daily cost of the $\mathrm{m}$ type of vessel (USD/day); $c^{l}$ represents the unit cost of loading containers on port; $c^{u}$ represents the unit cost of unloading containers on port; $G_{m}^{0}$ represents the other fixed cost per port for $m$ type of ship (USD/call), including berthing fee, mooring fee, port charge, and other fixed fees; $F_{m}$ represents the fuel consumption by the main engines of $m$ type of vessel (ton/day); $A_{m}$ represents the fuel consumption by the auxiliary of $m$ type of vessel (ton/day); $B_{m}$ represents the capacity of $m$ type of vessel (TEU); $P_{H F O}$ denotes crude oil prices (USD/ton); $P_{M F O}$ denotes light oil prices $(\mathrm{USD} / \mathrm{T}) ; f^{\text {day }}(t p)$ represents the daily profit of the shipping company. 


\section{Model Formulation}

\subsection{Case1: Model without Carbon Emission Tax}

4.1.1. Relationship between Origin to Destination (OD) Demand between Ports and Total Cargo Volume of each Segment. $k$ represents the segment, $Y_{k}$ represents the total amount of goods on the segment $k$. When there is a demand for goods between the two ports, the goods are transported from port $i$ to port $j$. Use $q_{i j}$ to indicate the amount of container transported from port $i$ to port $j$, as shown in Figure 1: When the port 2 has cargo $q_{24}$ to be transported to the port 4 , it will pass through the 2-3 segment and the 3-4 segment. When the port 1 has cargo $q_{13}$ to be transported to the port 3, it will pass through the 1-2 segment and the 2-3 segment. It can be seen that the total amount of goods transported on the 2 segment is $q_{24}+q_{13}$. Similarly, the total amount of goods $Y_{k}$ on the segment $k$ can be expressed as $Y_{k}=\sum_{j=k+1}^{N} \sum_{i=1}^{k} q_{i j}$.

4.1.2. Relationship between Speed and Sailing Time and the Number of Ships. Total time $T$ for a single vessel to complete a voyage consists of the sailing time at sea, loading and unloading time at the port, and pilotage time into and out of the port, $t^{s}=$ voyage/voyage time.

$$
T=D / \sum_{m \in M}\left(x_{m} v_{m}\right)+\sum_{i=1}^{N} Q_{i} / l+N \cdot t_{p i l} .
$$

$Q_{i}$ represents the loading and unloading of port $I, Q_{i}=$ $\sum_{j=1}^{N} q_{i j}+q_{j i}, \sum_{j=1}^{N} q_{i j}$ represents the port $i$ export volume, $\sum_{j=1}^{N} q_{j i}$ represents the port $i$ import volume. Weekly boat number: $n_{m}=T /(24 \times 7)=T / 168$

$$
n_{m}=\frac{T}{168}=\frac{1}{168}\left(D / \sum_{m \in M}\left(x_{m} v_{m}\right)+\sum_{i=1}^{N} \frac{Q_{i}}{l}+N t_{p i l}\right)
$$

4.1.3. Fleet Daily Income $f(r)$ Represents Average Daily Income of all Ships in the Fleet.

$$
f(r)=\sum_{i=0}^{N-1} \sum_{j=0}^{N-1} q_{i j} \cdot r_{i j} / 7
$$

\subsubsection{Fleet Cost}

(1) Daily operating cost $f(o c)_{\text {day }}$ including Ship staff, ship depreciation, financial expenses, office supplies, personnel management fees, and other expenses

$$
f(o c)_{\mathrm{day}}=\sum_{m \in M}\left(x_{m} C_{m} n_{m}\right)
$$

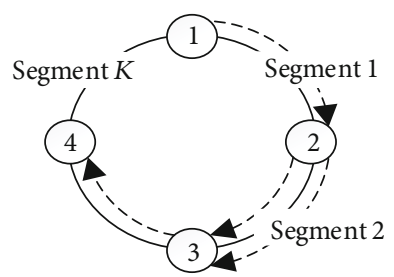

FIgURE 1: Relationship between the total cargo volume of each segment.

(2) Fleet daily average port cost $f(p)$ including port handling charges and port charges (including parking fees, cable cancellation fees, and port charges)

$$
f(p)=\sum_{i=1}^{N} \sum_{j=1}^{N}\left(q_{i j} C^{l}+q_{j i} C^{u}\right) / 7+N \cdot \sum_{i=1}^{N}\left(G_{m}^{0} x_{m}\right) / 7
$$

(3) Average daily fuel consumption $f(v)_{\text {day }}$

The per-trip fuel consumption of the main engine follows the so-called cubic law of design speed and operational speed, $F_{m}\left(v_{m} / v_{m}^{0}\right)^{3}$ indicates the fuel consumption of the ship's main engine [13]. The main engine and auxiliary machine of the ship use different fuels. Usually, the main engine uses heavy oil, and the auxiliary machine uses light oil. Therefore, total fuel consumption $F$ of the fleet on the route can be expressed as formula (6), and the average daily fuel consumption cost is the formula (7).

$$
\begin{aligned}
F & =\sum_{m \in M}\left(x_{m} F_{m}\left(\frac{v_{m}}{v_{m}^{0}}\right)^{3} \frac{D}{168 v_{m}}\right)+\sum_{m \in M} A_{m} \cdot x_{m} \cdot n \\
& =\sum_{m \in M} x_{m} F_{m}\left(\frac{v_{m}}{v_{m}^{0}}\right)^{3} \frac{D}{168 v_{m}}+\sum_{m \in M} A_{m} \cdot x_{m} \cdot n,
\end{aligned}
$$

$$
\begin{aligned}
f(v)_{\mathrm{day}}= & \sum_{m \in M} x_{m} F_{m}\left(\frac{v_{m}}{v_{m}^{0}}\right)^{3} \cdot \frac{D}{v_{m} \cdot 168} \cdot P_{\mathrm{HFO}} \\
& +\sum_{m \in M} A_{m} \cdot x_{m} \cdot n \cdot P_{\mathrm{MFO}} .
\end{aligned}
$$

Therefore, the shipowner's decision model in Casel can be represented as follows:

$$
\begin{aligned}
\max f^{\mathrm{day}}(t p)= & \sum_{i=1}^{N} \sum_{j=1}^{N} \frac{q_{i j} \cdot r_{i j}}{7}-\sum_{m \in M} x_{m} F_{m}\left(\frac{v_{m}}{v_{m}^{0}}\right)^{3} \cdot \frac{D}{v_{m} \cdot 168} \\
& \cdot P_{\mathrm{HFO}}-\sum_{m \in M} A_{m} \cdot x_{m} \cdot n \cdot P_{\mathrm{MFO}}-\sum_{m \in M}\left(x_{m} C_{m} n\right) \\
& -\sum_{i=1}^{N} \sum_{j=1}^{N}\left(q_{i j} C^{l}+q_{j i} C^{u}\right) / 7-\sum_{m \in M}\left(x_{m} G_{m}^{0}\right) \cdot N / 7
\end{aligned}
$$


s.t. :

$$
\begin{gathered}
x_{m}=0 \text { or } 1 \\
\sum_{m \in M} x_{m}=1 \\
\max \left(Y_{k}\right) \leq \sum_{m \in M} B_{m} x_{m} \\
v_{m}^{\min } \leq v_{m} \leq v_{m}^{\max } \\
k=1,2, \cdots, N ; \\
i, j=1,2, \cdots, N ; \\
m \in M .
\end{gathered}
$$

(9) and (10) indicate that the same type of ship is deployed on the route; (11) indicates that the ship capacity limit; (12) indicates that speed limit; equations (13) and (14) are nonnegative and integer constraints.

4.2. Case2: Model considering Carbon Caps. The carbon limit refers to the operation of the company in accordance with the defined carbon emission allowance. When the carbon emission quota is insufficient or excessive, the company cannot purchase or sell carbon emission rights to the carbon limit and the trading market. Therefore, the carbon restriction policy is a mandatory constraint for enterprises, and the carbon emission of this paper is limited to no more than $\theta$ (ton).

The relationship between speed and fuel consumption and carbon emissions: The carbon emissions of ships depend on the fuel consumption of ships and the carbon emission factors of fuels in a certain period of time. The carbon emission factors are slightly different in each literature, and the coefficient of the Intergovernmental Panel on Climate Change (IPCC) is adopted [32]. That is, $1 \mathrm{t}$ marine fuel produces $3.17 \mathrm{t}$ of $\mathrm{CO}_{2}$, so the fleet's average daily $\mathrm{C}_{2}$ emissions $Q_{c o 2}$ can be expressed as $Q_{c o 2}=3.17 F$.

Therefore, the shipowner's decision model in Case 2 can be represented as follows:

$$
\begin{aligned}
\max f^{\text {day }}(t p)= & \sum_{i=1}^{N} \sum_{j=1}^{N} \frac{q_{i j} \cdot r_{i j}}{7}-\sum_{m \in M} x_{m} F_{m}\left(\frac{v_{m}}{v_{m}^{0}}\right)^{3} \cdot \frac{D}{v_{m} \cdot 168} \\
& \cdot P_{\mathrm{HFO}}-\sum_{m \in M} A_{m} \cdot x_{m} \cdot n \cdot P_{\mathrm{MFO}}-\sum_{m \in M}\left(x_{m} C_{m} n\right) \\
& -\sum_{i=1}^{N} \sum_{j=1}^{N}\left(q_{i j} C^{l}+q_{j i} C^{u}\right) / 7-\sum_{m \in M}\left(x_{m} G_{m}^{0}\right) \cdot N / 7
\end{aligned}
$$

s.t. :

$$
\begin{gathered}
Q_{c o_{2}} \leq \theta \\
x_{m}=0 \text { or } 1 \\
\sum_{m \in M} x_{m}=1
\end{gathered}
$$

$$
\begin{gathered}
\max \left(Y_{k}\right) \leq \sum_{m \in M} B_{m} x_{m} \\
v_{m}^{\min } \leq v_{m} \leq v_{m}^{\max } \\
k=1,2, \cdots, N ; \\
i, j=1,2, \cdots, N ; \\
m \in M .
\end{gathered}
$$

(16) indicates the carbon limit constraint.

4.3. Case3: Model considering Carbon Emissions Tax. Carbon emissions tax refers to the policy of levying a certain carbon emission tax on carbon emissions in the course of business operations. Carbon emissions tax is levied on a carbon tax based on carbon emissions. According to the ship's carbon dioxide emissions, the $\delta_{1}$ quantitative carbon tax (USD/ton) is imposed per ton.

$$
C_{\mathrm{co}_{2}}=Q_{\mathrm{co}_{2}} \cdot \delta_{1}=3.17 \mathrm{~F} \cdot \delta_{1} .
$$

Therefore, the shipowner's decision model in Case 3 can be represented as follows:

$$
\begin{aligned}
\max f^{\text {day }}(t p)= & \sum_{i=1}^{N} \sum_{j=1}^{N} \frac{q_{i j} \cdot r_{i j}}{7}-\sum_{m \in M} x_{m} F_{m}\left(\frac{v_{m}}{v_{m}^{0}}\right)^{3} \cdot \frac{D}{v_{m} \cdot 168} \\
& \cdot P_{\mathrm{HFO}}-\sum_{m \in M} A_{m} \cdot x_{m} \cdot n_{m} \cdot P_{\mathrm{MFO}}-\sum_{m \in M}\left(x_{m} C_{m} n_{m}\right) \\
& -\sum_{i=1}^{N} \sum_{j=1}^{N}\left(q_{i j} C^{l}+q_{j i} C^{u}\right) / 7-\sum_{m \in M}\left(x_{m} G_{m}^{0}\right) \\
& \cdot N / 7-3.17 \cdot F \cdot \delta_{1}
\end{aligned}
$$

s.t. : Formulas (9), (10), (11), (12), (13), and (14).

4.4. Case 4: Model considering Carbon Cap-and-Trade. Carbon cap-and-trade means that the carbon emissions of enterprises are controlled by carbon emission limits. However, when carbon emission quotas are insufficient, enterprises can purchase carbon emission rights from the carbon trading market, which increases the cost of carbon emissions for shipping companies. When carbon credits are excessive, companies can go to the carbon trading market to sell excess carbon credits, gain additional revenue, and increase carbon sales revenue for shipping companies. Use market mechanisms to establish legal emission rights and allow such rights to be traded like commodities for carbon emission control. The price per ton of carbon traded is $p_{e}$, and the carbon emission limit assigned to the route is $\theta$. Fleet daily carbon emission $\operatorname{cost} C_{\mathrm{co}_{2}}=\left(\theta-Q_{\mathrm{co}_{2}}\right) \cdot p_{e}=(\theta-3.17 \cdot F) \cdot p_{e}$. 


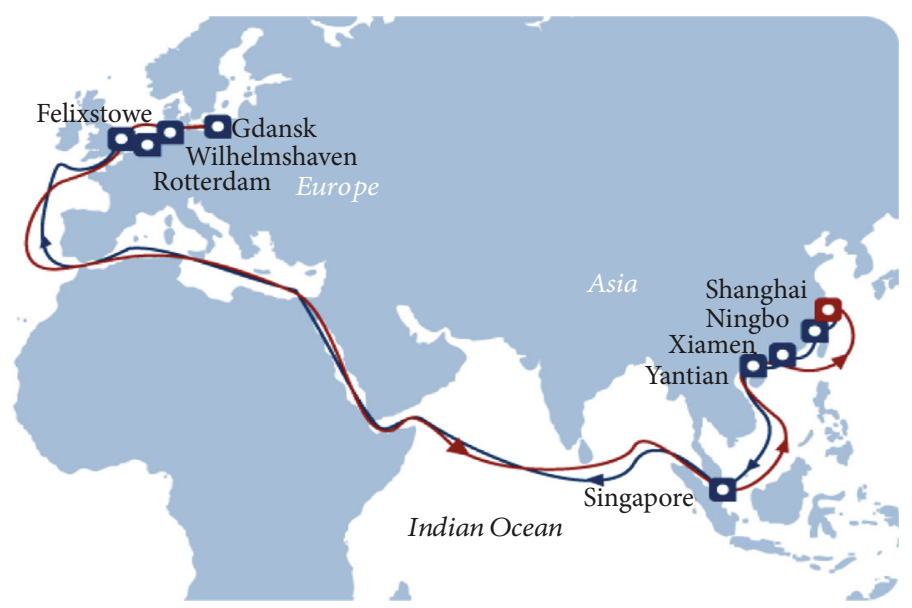

FIgURE 2: The European route of COSCO SHIPPING.

TABle 1: Data of each ship type.

\begin{tabular}{|c|c|c|c|c|c|c|c|c|c|}
\hline Name of vessel & $m$ & $\begin{array}{c}B_{m} \\
(\mathrm{TEU})\end{array}$ & $\begin{array}{c}F_{m} \\
\text { (ton/day) }\end{array}$ & $\begin{array}{c}A_{m} \\
\text { (ton/day) }\end{array}$ & $\begin{array}{c}v_{m}^{0} \\
(\mathrm{Kn} / \mathrm{h}) \\
\end{array}$ & $\begin{array}{c}v_{m}^{\min } \\
(\mathrm{Kn} / \mathrm{h})\end{array}$ & $\begin{array}{c}v_{m}^{\max } \\
(\mathrm{Kn} / \mathrm{h}) \\
\end{array}$ & $\begin{array}{c}c_{m} \\
\text { (USD/day) }\end{array}$ & $\begin{array}{c}G_{m}^{0} \\
\text { (USD/call) }\end{array}$ \\
\hline XIN ZHANG ZHOU & 1 & 4253 & 139.5 & 6.33 & 24.2 & 11.34 & 25.15 & 9000 & 3001 \\
\hline XIN WENZHOU & 2 & 4738 & 82 & 4.3 & 18 & 8.44 & 18.7 & 10026 & 3344 \\
\hline XIN YAN TIAN & 3 & 5668 & 202 & 7.81 & 25.7 & 12.05 & 26.7 & 11994 & 4000 \\
\hline COSCO THAILAND & 4 & 8501 & 250 & 10.47 & 25.6 & 12 & 26.6 & 17989 & 6000 \\
\hline XIN SHANGHAI & 5 & 9572 & 248.2 & 10.43 & 25.2 & 11.22 & 26.73 & 20255 & 6204 \\
\hline COSCO ASIA & 6 & 10036 & 250 & 12.75 & 24.8 & 11.04 & 25.8 & 21238 & 6505 \\
\hline COSCO FAITH & 7 & 13114 & 274.9 & 13.2 & 24.7 & 11 & 26.2 & 27751 & 8500 \\
\hline CSCLJUPITER & 8 & 14074 & 262 & 14.51 & 25.1 & 11.18 & 26.62 & 29783 & 9122 \\
\hline CSCLPACIFIC OCEAN & 9 & 18982 & 195.5 & 13.768 & 18 & 10 & 24.6 & 40169 & 13000 \\
\hline $\begin{array}{l}\text { COSCO SHIPPING } \\
\text { VIRGO }\end{array}$ & 10 & 20119 & 168 & 10.263 & 19 & 8.46 & 22.5 & 42575 & 13040 \\
\hline
\end{tabular}

Therefore, the shipowner's decision model in Case 4 can be represented as follows:

$$
\begin{aligned}
\max f^{\mathrm{day}}(t p)= & \sum_{i=1}^{N} \sum_{j=1}^{N} \frac{q_{i j} \cdot r_{i j}}{7}-\sum_{m \in M} x_{m} F_{m}\left(\frac{v_{m}}{v_{m}^{0}}\right)^{3} \cdot \frac{D}{v_{m} \cdot 168} \\
& \cdot P_{\mathrm{HFO}}-\sum_{m \in M} A_{m} \cdot x_{m} \cdot n_{m} \cdot P_{M F O}-\sum_{m \in M}\left(x_{m} C_{m} n_{m}\right) \\
& -\sum_{i=1}^{N} \sum_{j=1}^{N}\left(q_{i j} C^{l}+q_{j i} C^{u}\right) / 7-\sum_{m \in M}\left(x_{m} G_{m}^{0}\right) \cdot N / 7 \\
& -(\theta-3.17 \cdot F) \cdot p_{e}
\end{aligned}
$$

s.t. : Formulas (9), (10), (11), (12), (13), and (14).

\section{Numerical Example and Discussion}

5.1. Description of Parameter Settings. In order to evaluate the applicability of the proposed model and the effectiveness of the algorithm, this paper uses a real case study of COSCO SHIPPING Lines Co., Ltd. to select the actual case as shown in Figure 2, the ship starts from Shanghai Port and finally returns to Shanghai Port. And choose 10 kinds of ship types $(M=10)$ commonly used in COSCO as the research object. The ship information is shown as Table 1 (Source: Lloyd's Maritime Database).

The cargo transportation volume between ports (estimates from historical company data) and the freight rates between ports is shown as Tables 2 and 3. (Data Sources: COSCO SHIPPING Lines Co., Ltd.). We set the other parameters used in the model as follow (Data Sources: Clarkson, BIMCO): $P_{\mathrm{HFO}}=405 \mathrm{USD} / \mathrm{TON}, P_{\mathrm{MFO}}=609 \mathrm{USD} / \mathrm{TON}, D=$ $24836 \mathrm{kn}, l=150 \mathrm{TEU} / \mathrm{h}, c^{l}=c^{u}=65 \mathrm{USD} / \mathrm{TEU}, N=13, t_{p i l}=$ $2 \mathrm{~h}, p_{e}=50 \mathrm{USD} / \mathrm{TON}, \theta=2300 \mathrm{TON} /$ day.

5.2. Computation Results Analysis. The planning model is solved by using the MATLAB platform genetic algorithm, the algorithm is designed as follows:

\section{(1) Encoding:}

The decision variables of the optimization model in this paper are the speed of the ship and the choice of ship type. Real and binary coding is used. The total coding length (chromosome length) is set to $1+N$. The first locus is 
TABLE 2: The cargo transportation volume between ports, $q_{i j}$ (TEU).

\begin{tabular}{lccc}
\hline Port name & Singapore & Felixstowe & Rotterdam \\
\hline Shanghai & 570 & 1040 & 1040 \\
Ningbo & 570 & 1850 & 1850 \\
Xiamen & 380 & 1040 & 3040 \\
Yantian & 570 & 1850 & 1850 \\
Singapore & 0 & 1660 & 1850 \\
& Singapore & Xiamen & Shanghai \\
Rotterdam & 570 & 1040 & 1040 \\
Gdansk & 570 & 1850 & 1850 \\
Wilhelmshaven & 380 & 1040 & 3040 \\
Felixstowe & 570 & 1850 & 1850 \\
Singapore & 0 & 1660 & 1850 \\
\hline
\end{tabular}

TABLE 3: The freight rates between ports $r_{i j}$ (USD/TEU).

\begin{tabular}{lccc}
\hline Port name & Singapore & Felixstowe & Rotterdam \\
\hline Shanghai & 150 & 800 & 850 \\
Ningbo & 150 & 750 & 750 \\
Xiamen & 140 & 745 & 745 \\
Yantian & 100. & 600 & 650 \\
Singapore & 0 & 550 & 550 \\
& Singapore & Xiamen & Shanghai \\
Rotterdam & 550 & 900 & 900 \\
Gdansk & 550 & 900 & 900 \\
Wilhelmshaven & 550 & 900 & 900 \\
Felixstowe & 550 & 900 & 900 \\
Singapore & 0 & 150 & 150 \\
\hline
\end{tabular}

encoded by an integer real number. For example, 1 represents the first ship type, and 2 represents the second ship type. The last $N$ genes are binary coded, and the speed of the corresponding ship can be obtained by binary to decimal decoding. Considering the accuracy of the solution, $N$ is taken as 10 , so 0000000000 represents the lowest limit speed, 1111111111 represents the highest limit speed, and the possible speed value is divided into $2^{N}$ equal parts, each of which represents a speed value.

\section{(2) Generate initial population}

In order to ensure the quality of the solution set and the diversity of the population, we used a random method to generate the initial population and set the population size to 50 .

\section{(3) Fitness function}

The fitness function is usually directly expressed by the objective function, but due to the nonnegativity of the fitness value and the existence of some constraints, we need to convert the objective function. One is to add a penalty function, and the other is to add an appropriate positive number to ensure non-negative fitness. The fitness function used to construct the genetic algorithm is a combination function
TABLE 4: Original chromosome 1.

\begin{tabular}{lllllllllll}
\hline Ship type & \multicolumn{10}{c}{ Speed } \\
\hline 2 & 0 & 0 & 0 & 0 & 0 & 0 & 0 & 1 & 1 & 0 \\
\hline
\end{tabular}

TABLE 5: Original chromosome 2.

\begin{tabular}{lllllllllll}
\hline Ship type & \multicolumn{10}{c}{ Speed } \\
\hline 4 & 1 & 0 & 0 & 0 & 0 & 0 & 0 & 1 & 0 & 0 \\
\hline
\end{tabular}

TABle 6: New chromosome 1.

\begin{tabular}{lllllllllll}
\hline Ship type & \multicolumn{10}{c}{ Speed } \\
\hline 2 & 1 & 0 & 0 & 0 & 0 & 0 & 0 & 1 & 0 & 0 \\
\hline
\end{tabular}

TABle 7: New chromosome 2.

\begin{tabular}{lllllllllll}
\hline Ship type & \multicolumn{10}{c}{ Speed } \\
\hline 4 & 0 & 0 & 0 & 0 & 0 & 0 & 0 & 1 & 1 & 0 \\
\hline
\end{tabular}

formed by the constraints and the penalty function of the objective function. The specific form is as follows:

$$
\mathrm{FITV}=B-M\left[\max \left(Y_{k}\right) / \sum_{m \in M} B_{m} x_{m}\right]
$$

FITV represents the fitness function of the genetic algorithm, $M$ is a large positive number as a penalty weight, and $B$ is the objective function. [ ] is the rounding symbol, when $\max \left(Y_{k}\right) \leq \sum_{m \in M} B_{m} x_{m}$; the value is 0 , when $\max \left(Y_{k}\right)>\sum_{m \in M} B_{m} x_{m}$; the value is a nonzero positive number, which is an infinite positive number. The above becomes the penalty coefficient of the constraint condition $\max \left(Y_{k}\right) \leq \sum_{m \in M} B_{m} x_{m}$.

(4) Select operation

The strategy of combining roulette and elite retention is adopted, which can not only allow the better individuals of the previous generation to pass the good genes through inheritance, but also ensure that the optimal individual genes are not destroyed.

\section{(5) Crossover operator}

The information of different individuals in the population is exchanged through random probability to generate a larger individual population, which increases the complexity and diversity of the population in order to approximate the optimal solution. In the calculation of the genetic algorithm, the crossover operator, the key factor of crossover operation, is set to 0.8 in this paper. There are many ways of crossover operations. This article mainly studies the operation of two points crossover, that is, randomly pairing two individuals in a population. The original chromosomes are shown in Tables 4 and 5. 
TABLE 8: Computation results for different forms of carbon taxation.

\begin{tabular}{lcccc}
\hline & No carbon emissions constraints & Carbon emissions tax & Carbon caps & Carbon cap-and-trade \\
\hline Profit & 12415820 & 12385450 & 12300450 & 12413140 \\
Carbon emission & 2378.995 & 1900.934 & 2106.985 & 2378.992 \\
Carbon cost & 0 & 0 & 105349.3 & 2677.9 \\
Speed & 13.05418 & 11.09476 & 11.99497 & 13.05417 \\
Number of ships & 13 & 15 & 14 & 13 \\
Ship type & 10 & 10 & 10 & 10 \\
\hline
\end{tabular}

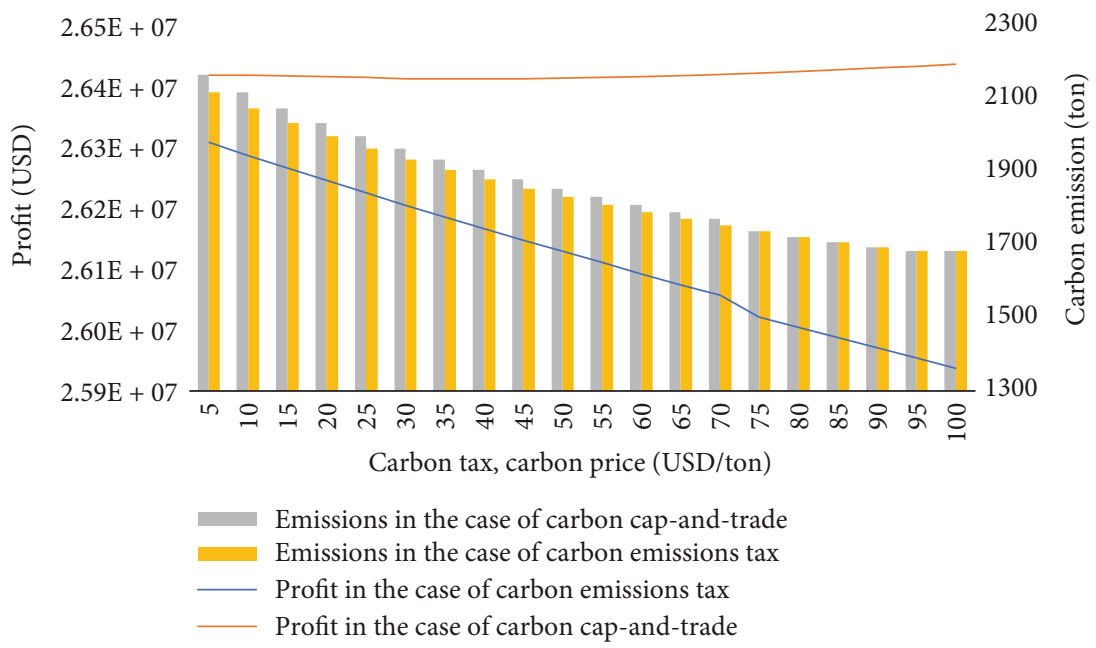

FIGURE 3: Results for comparison of carbon emissions tax and carbon cap-and-trade.

After a two-point crossing operation, the original chromosome has been transformed into a new chromosome. The results are shown in Tables 6 and 7.

\section{(6) Mutation operation}

The mutation operation satisfies the mutation probability $P_{m}$, and replaces certain gene values in paired chromosomes with their corresponding gene values to form new individuals in this way. Using the single point mutation operation, if the first genetic mutation is selected, randperm $(M, 1)$ will be used to replace the original value, that is, the random mutation of the ship type, and the last $N$ genetic mutations will be used to remove the binary coding on the genetic niche. Reverse operation, that is, $0 \rightarrow 1,1 \rightarrow 0$. In this study, the coefficient of variation was set to 0.05 .

\section{(7) Termination criteria}

The principle of termination is to reach the maximum number of genetic generations. The maximum algebra of this paper is 100 . The algorithm iteration algebra stops automatically when it reaches 100 , and outputs the optimal solution of the population, that is, the maximum profit.

The computation results are shown in Table 8.

It can be shown from Table 8 that carbon emissions tax, carbon caps, and carbon cap-and-trade cause the cost of the shipping company to increase, lower profits, lower average speeds, and reduce carbon emissions. The profit reduction ratios caused by the three-carbon emission policies were $0.24 \%, 0.93 \%$, and $0.02 \%$; the reductions in carbon emissions were $20.10 \%, 11.43 \%$, and $0.00012 \%$. In the case of carbon caps reduce carbon emissions most, which is the most direct way to control carbon emissions. However, the reduction of carbon emissions depends on the setting of emission caps, and the caps of emissions caps are subject to changes due to political negotiations and interest groups. In the case of carbon emissions tax has the greatest impact on the profit of the shipping company, carbon cap-and-trade form have the least impact on corporate profits. The form of carbon cap-and-trade is more likely to be favored by corporate support and decision makers, but its market regulation ability is weaker at present.

5.2.1. A Comparative Study of Carbon Emissions Tax and Carbon Cap-and-Trade. Carbon emissions tax and carbon cap-and-trade are the primary carbon emission reduction policy adopted by most countries that focus on carbon reduction. Based on the difference between carbon emissions tax and carbon cap-and-trade in terms of effect cost and emission reduction effect. Under the condition that other parameters are unchanged, the carbon tax and carbon trading price are continuously improved to perform multiple model calculations to obtain the results as shown in Figure 3.

It can be shown from Figure 3 that, as carbon trading prices and carbon taxes increase, carbon emissions continue to fall. When the carbon trading price and the carbon tax 


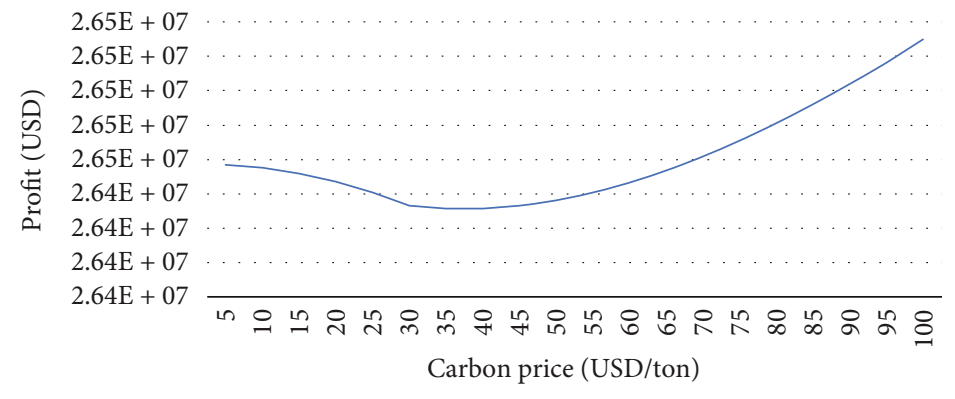

Figure 4: Profit curve of carbon cap-and-trade.

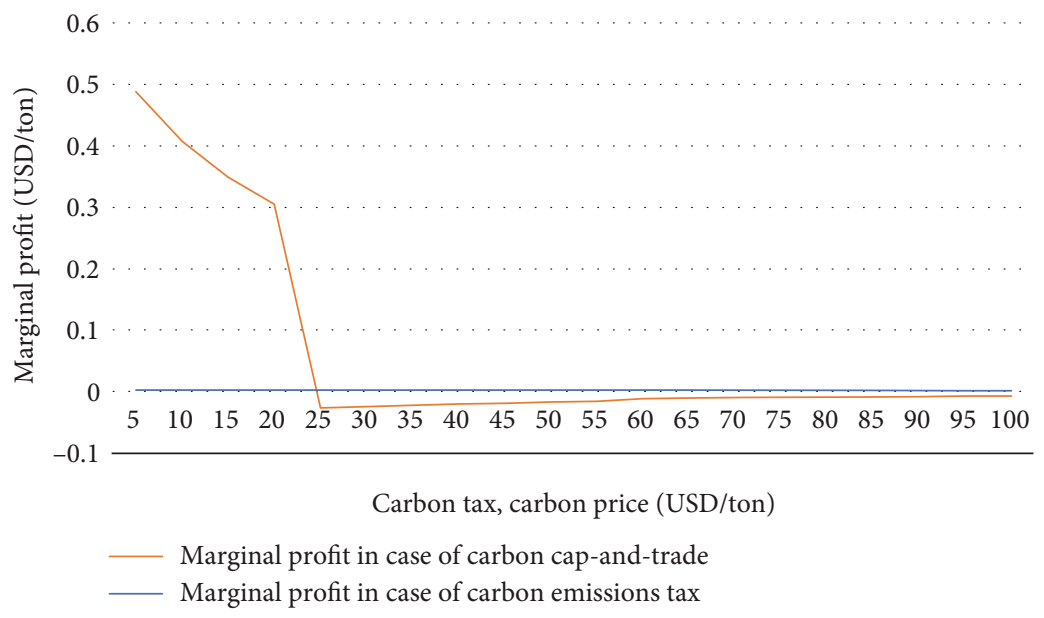

FIgURE 5: Marginal abatement costs.

reach 75 US dollars per ton, two forms of carbon emissions tend to be consistent. In the case of carbon cap-and-trade, the company's profit declines, but if the carbon trading price exceeds 50 US dollars per ton, the profit rises (as shown in Figure 4). The company's profit has been decreasing in the case of carbon emissions tax; it is found that the form of carbon cap-and-trade is welcomed by shipping companies and can meet the emission reduction requirements.

In the case of carbon cap-and-trade, it relies on market mechanisms to solve problems, prompting enterprises to actively implement emission reductions and is highly motivating. This mechanism allows emissions to be circulated; carbon reduction is no longer just a cost, it also creates opportunities to gain benefits. As the above result, it is also found that under the condition that the carbon trading market is mature, the profits of enterprises will not decrease but increase. For companies, it will make them more motivated to actively reduce emissions. However, the emission reduction in the form of carbon emissions tax is weaker at present. Because taxation is a compulsory measure, it is a cost that individuals or enterprises want to avoid. Therefore, the emission reduction actions promoted by carbon emissions tax are passive emission reductions, which is not conducive to improving the enthusiasm of enterprises.

\subsubsection{Balance Marginal Abatement Costs and Carbon} Emissions Costs. From the point of view of the shipping company, the goal of transportation optimization is to select the
TABLE 9: Different ship type optimization results.

\begin{tabular}{lcccc}
\hline & \multicolumn{2}{c}{$\begin{array}{c}\text { Carbon } \\
\text { emissions tax }\end{array}$} & \multicolumn{2}{c}{$\begin{array}{c}\text { Carbon } \\
\text { cap-and-trade }\end{array}$} \\
\hline$m$ & 9 & 10 & 9 & 10 \\
Fuel cost & 374886.6 & 299937.7 & 408081.9 & 266974.5 \\
$N$ & 15 & 14 & 14 & 13 \\
Speed & 11.09476 & 11.99497 & 11.99497 & 13.05417 \\
Carbon emission & 2588.384 & 2106.985 & 2871.269 & 2378.992 \\
Profit & 12195020 & 12300450 & 12319770 & 12411560 \\
\hline
\end{tabular}

best speed to maximize profits within the scope of meeting the emission reduction task. When companies choose the highest value between the profit values, they often do not consider the increase in carbon emissions, as long as they meet the market-defined emission reduction targets. To this end, through the marginal abatement costs, explore the impact of market emission reduction policies on corporate costs. The marginal abatement cost is equal to the ratio of the amount of carbon reduction to the cost of abatement, that is, the economic cost of reducing one unit of carbon emissions (the carbon tax cost or the carbon transaction amount for the shipping company).

It can be shown from Figure 5 that the marginal abatement costs in the case of carbon emissions tax are all greater than zero; it shows that there is a certain economic cost to 


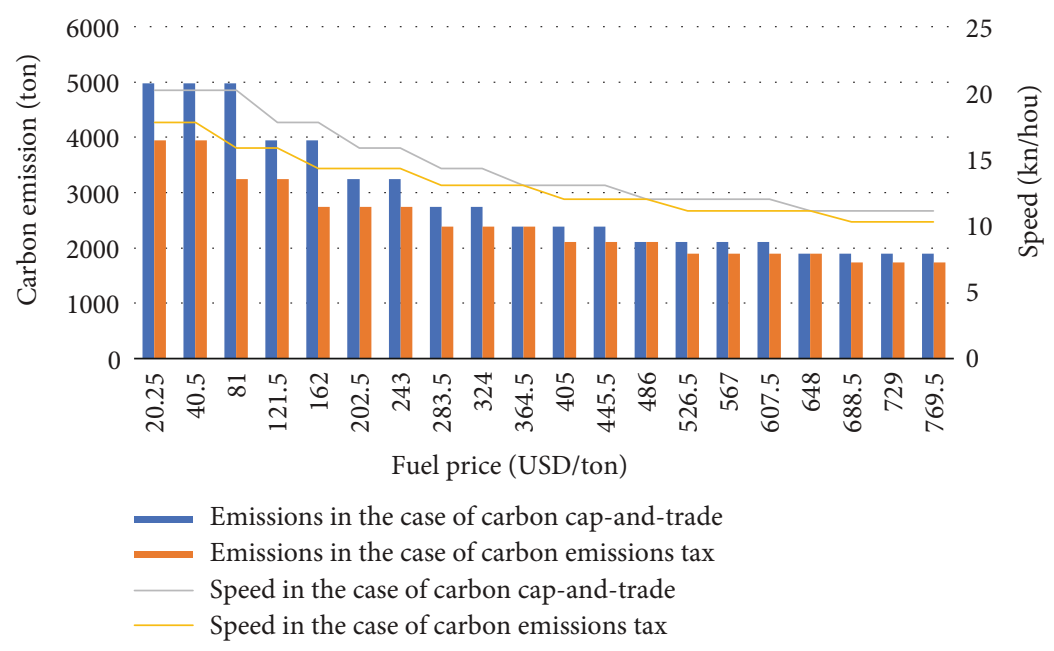

FIGURE 6: Computation results for oil price change.

reduce one unit of carbon emissions. In the case of carbon cap-and-trade, when the carbon trading price is less than 50 US dollars, the marginal abatement cost is greater than zero and greater than the marginal abatement cost in the case of carbon emissions tax, indicating that the enterprise needs to pay a certain economic cost to reduce one unit of carbon emissions and the cost is greater than the carbon emissions tax form; When the carbon trading price is greater than 50 US dollars, the marginal abatement cost is less than zero, which means that enterprises can obtain certain income without reducing the economic cost of one unit of carbon emissions. Therefore, in the current carbon trading market is not mature enough, compared with the carbon emissions tax form, the carbon cap-and-trade form will be less stimulating for shipping companies to reduce emissions. As the carbon trading market continues to mature, carbon trading prices continue to increase, shipping companies will greatly increase their enthusiasm for emission reduction. From the perspective of emission reduction effect and corporate enthusiasm, the carbon cap-and-trade form is better and more suitable for the sustainable development of shipping.

5.2.3. Ship Size Impact on Carbon Emissions. It can be shown from Table 9 that large-scale ships have the dual advantages of lower fuel costs and lower carbon emissions than ships with smaller capacities. It had a large-scale increase of ship transportation capacity and the significant reduction in shipping energy consumption, while reducing harmful ecological emissions. Driven by economic and environmental protection, large-scale ships are the trend of global low-carbon economic development and sustainable shipping development.

\subsection{Sensitivity Analysis}

5.3.1. Fuel Price Change. At present, most shipping companies use speed changes to control costs [33]. It can be shown from Figure 4 that in the short term, low oil prices have a certain effect on shipping companies to reduce costs. When oil prices fall, they choose to increase the speed of the ship, reduce the ship's input, or increase the number of flights.
The increase in oil prices leads to a decrease in the speed of the ship and an increase in the input cost of the ship. At the same time, from Figure 6, it is found that the oil price is low and the carbon emission is high, so the low oil price will have a negative impact on energy conservation and emission reduction. Moreover, in the perspective of shipping sustainability, low oil prices will reduce the enthusiasm of enterprises for reducing emissions. For example, some management software and fuel additives used by COSCO in energy conservation and emission reduction require certain costs. If low oil prices continue, these inputs are basically not meaningful.

5.3.2. Loading and Unloading Efficiency Changes. It can be shown from Figure 7 that improved port loading and unloading efficiency leads to shorter sailing time, the number of shipping vessels decreases, and the cost of the ship reduces. Increasing handling efficiency can reduce total costs and does not necessarily reduce carbon emissions (depending on the number of vessels) but the overall trend in carbon emissions declines. Therefore, in the perspective of sustainable shipping development, the port's continuous improvement of loading and unloading efficiency is the general trend.

\section{Conclusions}

The paper analyzes the impact of no carbon emissions constraints, carbon emissions tax, carbon caps, and carbon cap-and-trade on liner shipping optimization. Results show that they all cause a reduction in the profit of the ship liner transport company, which will also cause the average speed to decrease and reduce carbon emissions. Carbon caps form is the most direct emission reduction method for emission reduction. Carbon emissions tax form has the greatest impact on the profit of the shipping company. The carbon cap-andtrade form is more easily supported by the enterprise; however, the carbon trading price is too low and its market regulation is weak. At the same time, it is found that the largescale ship has the dual advantages of lower fuel cost and lower carbon emissions. 


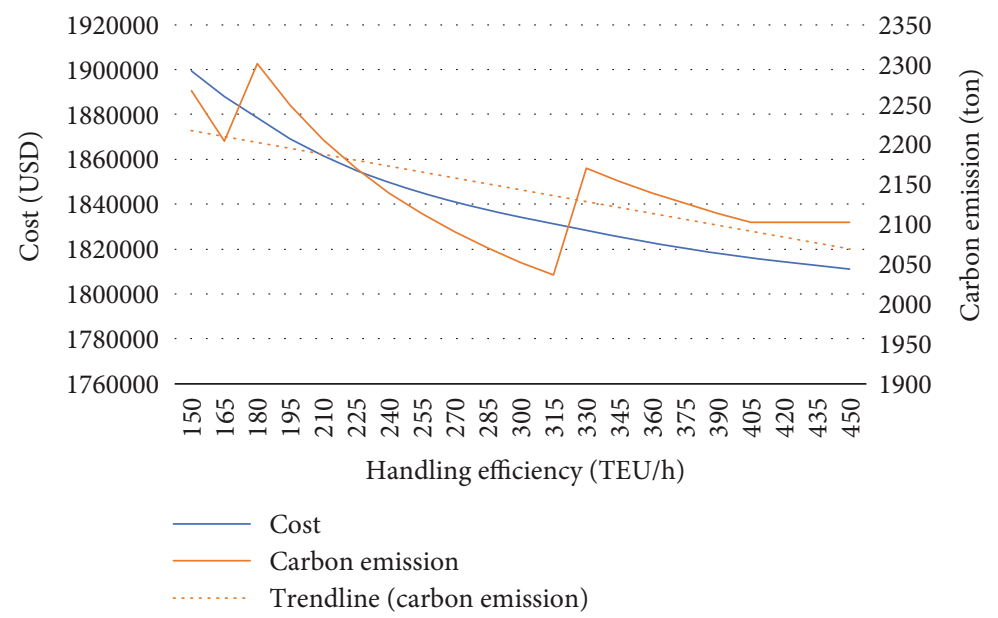

FIGURE 7: Computation results for loading and unloading efficiency changes.

The carbon emissions tax and carbon cap-and-trade form are compared and analyzed. It is found that carbon cap-and-trade form relies on market mechanism to solve the climate problem and encourages enterprises to actively implement emission reduction and incentive. Carbon emissions tax form is a compulsory measure of emission reduction, and the incentive is weak. From the perspective of emission reduction effect and corporate enthusiasm, the carbon cap-and-trade form is better and more suitable for the sustainable development of shipping. Sensitivity analysis found that in the short term, low oil prices have a certain effect on shipping companies to reduce costs, while high carbon emissions have a negative impact on emissions reduction. In the perspective of shipping sustainability, low oil prices will reduce the enthusiasm of enterprises for reducing emissions. Increasing handling efficiency can not necessarily reduce carbon emissions (depending on the number of vessels) but the overall trend in carbon emissions declines.

This paper studies the impact of carbon emission policy on ship transportation optimization from the perspective of shipping companies. However, the benefit to shippers and other stakeholders in the supply chain has not been adequately demonstrated. Combined influence of different carbon emission policies, how to spread the benefits along the shipping supply chains requires more research.

\section{Data Availability}

All data generated or analyzed during this study are included in this article, more detailed data or code please visit: https:// figshare.com/s/2b6be4ad8f703a01ce38.

\section{Conflicts of Interest}

The authors declare that there is no conflict of interest regarding the publication of this paper.

\section{Funding}

This study was funded by the special fund for the promotion of high-quality economic development in Guangdong
Province (use of marine economic development). Project No.: Department of Natural Resources of Guangdong Province (Grant No. [2020]071).

\section{References}

[1] C. Wang and C. Xu, "Sailing speed optimization in voyage chartering ship considering different carbon emissions taxation," Computers \& Industrial Engineering, vol. 89, pp. 108115,2015

[2] M. Jin, N. A. Granda-Marulanda, and I. Down, "The impact of carbon policies on supply chain design and logistics of a major retailer," Journal of Cleaner Production, vol. 85, pp. 453-461, 2014.

[3] C. Böhringer, "Two decades of European climate policy: a critical appraisal," Review of Environmental Economics and Policy, vol. 8, no. 1, pp. 1-17, 2014.

[4] J. A. Vallejo-Pinto, L. Garcia-Alonso, R. Á. Fernández, and I. Mateo-Mantecón, "Iso-emission map: A proposal to compare the environmental friendliness of short sea shipping $v s$ road transport," Transportation Research Part D: Transport and Environment, vol. 67, pp. 596-609, 2019.

[5] Ø. Buhaug, J. J. Corbett, and Ø. Endresen, Second imo ghg study 2009, International maritime organization (IMO), London, UK, 2009.

[6] P. N. Hoffmann, M. S. Eide, and Ø. Endresen, "Effect of proposed $\mathrm{CO} 2$ emission reduction scenarios on capital expenditure," Maritime Policy \& Management, vol. 39, no. 4, pp. 443-460, 2012.

[7] X. Qi and D. P. Song, "Minimizing fuel emissions by optimizing vessel schedules in liner shipping with uncertain port times," Transportation Research Part E, vol. 48, no. 4, pp. 863-880, 2012.

[8] J.-K. Woo and D. S.-H. Moon, "The effects of slow steaming on the environmental performance in liner shipping," Maritime Policy \& Management, vol. 41, no. 2, pp. 176-191, 2014.

[9] IMO, World Maritime Day- A Concept of a Sustainable Maritime Transport System, International Maritime Organization, London, 2013.

[10] D. Ronen, "Cargo ships routing and scheduling: survey of models and problems," European Journal of Operational Research, vol. 12, no. 2, pp. 119-126, 1983. 
[11] S. Wang and Q. Meng, "Sailing speed optimization for container ships in a liner shipping network," Transportation Research Part E, vol. 48, no. 3, pp. 701-714, 2012.

[12] V. N. Armstrong, "Vessel optimisation for low carbon shipping," Ocean Engineering, vol. 73, pp. 195-207, 2013.

[13] P. Cariou, "Is slow steaming a sustainable means of reducing CO2 emissions from container shipping?," Transportation Research Part D, vol. 16, no. 3, pp. 260-264, 2011.

[14] H. Lindstad, B. E. Asbjørnslett, and A. H. Strømman, "Reductions in greenhouse gas emissions and cost by shipping at lower speeds," Energy Policy, vol. 39, no. 6, pp. 3456-3464, 2011.

[15] J. Yin, L. Fan, Z. Yang, and K. X. Li, "Slow steaming of liner trade: its economic and environmental impacts," Maritime Policy \& Management, vol. 41, no. 2, pp. 149-158, 2014.

[16] H. Lindstad and G. S. Eskeland, "Low carbon maritime transport: How speed, size and slenderness amounts to substantial capital energy substitution," Transportation Research Part D, vol. 41, pp. 244-256, 2015.

[17] E. Y. C. Wong, A. H. Tai, H. Y. K. Lau, and M. Raman, “An utility-based decision support sustainability model in slow steaming maritime operations," Transportation Research Part E: Logistics and Transportation Review, vol. 78, pp. 57-69, 2015.

[18] H. N. Psaraftis, "Speed optimization vs speed reduction: the choice between speed limits and a bunker levy," Sustainability, vol. 11, no. 8, p. 2249, 2019.

[19] J. G. Kim, H. J. Kim, H. B. Jun, and C. M. Kim, "Optimizing ship speed to minimize total fuel consumption with multiple time windows," Mathematical Problems in Engineering, vol. 2016, Article ID 3130291, 7 pages, 2016.

[20] J.-G. Kim, H.-J. Kim, and P. T.-W. Lee, “Optimising containership speed and fleet size under a carbon tax and an emission trading scheme," International Journal of Shipping and Transport Logistics, vol. 5, no. 6, pp. 571-590, 2013.

[21] J. J. Corbett, H. Wang, and J. J. Winebrake, “The effectiveness and costs of speed reductions on emissions from international shipping," Transportation Research Part D: Transport and Environment, vol. 14, no. 8, pp. 593-598, 2009.

[22] H. N. Psaraftis and C. A. Kontovas, "Balancing the economic and environmental performance of maritime transportation," Transportation Research Part D: Transport and Environment, vol. 15, no. 8, pp. 458-462, 2010.

[23] V. Windeck and H. Stadtler, “A liner shipping network design-routing and scheduling impacted by environmental influences," in Network Optimization, J. Pahl, T. Reiners, and S. Voß, Eds., vol. 6701 of Lecture Notes in Computer Science, pp. 574-576, Springer, Berlin, Heidelberg, 2011.

[24] P. Franc and L. Sutto, "Impact analysis on shipping lines and European ports of a cap- and-trade system on CO2emissions in maritime transport," Maritime Policy \& Management, vol. 41, no. 1, pp. 61-78, 2013.

[25] Y.-T. Chang and D. Danao, "Green shipping practices of shipping firms," Sustainability, vol. 9, no. 5, p. 829, 2017.

[26] A. Michaelowa and K. Krause, "International maritime transport and climate policy," Intereconomics, vol. 35, no. 3, pp. 127-136, 2000.

[27] X. Chen and X. Wang, "Effects of carbon emission reduction policies on transportation mode selections with stochastic demand," Transportation Research Part E: Logistics and Transportation Review, vol. 90, pp. 196-205, 2016.
[28] O. Mæstad, A. J. Evensen, and L. Mathiesen, International climate policy: consequences for shipping, SNF, 2000.

[29] T. C. Lirn, H. W. Lin, and K. C. Shang, "Green shipping management capability and firm performance in the container shipping industry," Maritime Policy \& Management, vol. 41, no. 2, pp. 159-175, 2014.

[30] Y. Xing, H. Yang, X. Ma, and Y. Zhang, "Optimization of ship speed and fleet deployment under carbon emissions policies for container shipping," Transport, vol. 34, no. 3, pp. 260 274, 2019.

[31] M. Zhu, K. F. Yuen, J. W. Ge, and K. X. Li, "Impact of maritime emissions trading system on fleet deployment and mitigation of $\mathrm{CO}_{2}$ emission," Transportation Research Part D: Transport and Environment, vol. 62, pp. 474-488, 2018.

[32] C. Kontovas and H. N. Psaraftis, "Reduction of emissions along the maritime intermodal container chain: operational models and policies," Maritime Policy \& Management, vol. 38, no. 4, pp. 451-469, 2011.

[33] H. N. Psaraftis and C. A. Kontovas, "Speed models for energyefficient maritime transportation: a taxonomy and survey," Transportation Research Part C: Emerging Technologies, vol. 26, pp. 331-351, 2013. 